\title{
Digital transformation of existing cities
}

\author{
Elena Akhmedova ${ }^{1, *}$, and Tatyana Vavilonskaya ${ }^{2}$ \\ ${ }^{1}$ Samara State Technical University, Architecture and Construction Academy, 443001, Samara, \\ Molodogvardeyskaya Street 194, Russia
}

\begin{abstract}
The article focuses on the range of problems arising on the way of innovative technologies implementation in the structure of existing cities. The concept of intellectualization of historic cities, as illustrated by Samara, is offered, which was chosen for the realization of a large Russian project "Smart City. Successful Region" in 2018. One of the problems was to study the experience of information hubs projecting with the purpose of determination of their priority functional directions. The following typology of information hubs was made: scientific and research ones, scientific and technical ones, innovative and cultural ones, cultural and informational ones, scientific and informational ones, technological ones, centres for data processing, scientific centres with experimental and production laboratories. As a result of the conducted research, a suggestion on smart city's infrastructure is developed, the final levels of innovative technologies implementation in the structure of historic territories are determined. A model suggestion on the formation of a scientific and project centre with experimental and production laboratories branded as named "Park-plant" is developed. Smart (as well as real) city technologies, which are supposed to be placed on the territory of "Park-plant", are systematized. The organizational structure of the promotion of model projects is offered according to the concept of "triad of development agents", in which the flagship university - urban community - park-plant interact within the project programme. The effects of the development of the being renovated territory of the historic city centre are enumerated.
\end{abstract}

\section{Introduction}

Modern technologies are being implemented in the structure of a modern city more and more actively [1]. The problem in historic cities is twofold: on the one hand, historic cities as the centres of attraction for tourist activity need to broaden the information field due to the application of innovative technologies, on the other hand, the consistent implantation of innovations in the being formed by centuries environment of the historic city centres is one of the most complex tasks of the modern project practice.

The notion of a "smart city" appears, but to what extent it is applicable to the already formed urban unities is yet to be estimated. The main parameters of smart cities are: constructability, resource saving, intellectualization, and focus on the quality of life. The criteria of city intellectualization are environmental compatibility, safety, energy efficiency,

\footnotetext{
*Corresponding author: dir_inst_arch@bk.ru
} 
maximum comfort of life-sustaining activity $[2,3]$.

The aim of this research became a new acceptable for the historically formed Russian cities concept of intellectualization as a special approach to urban development, under which digital technologies are used to enhance the efficiency of work of the urban infrastructure, reduction of resource consumption and operative management. Innovative technologies determine digital transformation of the formed urban structures. In smart cities it is necessary to create holistic infrastructure managed by the centres of data processing capable to preserve big volumes of information being received from different systems and objects of a "smart city". The core of the smart city can be an information hub that as a large-scale object of an absolutely new type in its unique characteristics corresponds to the function of the municipal city centre.

The following tasks were set in the course of research:

- to distinguish the range of general and local problems on the way of innovative technologies implementation in the structure of existing cities;

- to analyse positive international and national experience of innovative centres creation based on the concept of cities' intellectualization;

- to form a principally new concept of smart city information infrastructure typology acceptable for the implementation in the conditions of existing cities (as illustrated by Samara);

- to determine the finished ground levels of innovative technologies implementation in the structure of historic territories, to offer possible model projects of their implementation (as illustrated by Samara).

\section{Materials and methods}

The method of complex analysis of international and national experience in the intellectualization of existing cities, historical and geographical and typological approaches to the systematization of international and national experience of information technologies implementation in the structure of historic territories were used in the research.

It stands to mention that the first information centres, i.e. hubs of Europe appear in the 1980s in Amsterdam, London and Frankfurt on the Main that represent historic cities with the centuries-long history of development. Only in XXI century "smart city" is becoming a programme strategy of new cities' development. Information hubs initially were situated in industrial zones and represented utility constructions. With the development of innovative technologies as a special sector of economics information hubs and intellectual objects become an inseparable part of the urban environment, and the task of projecting such objects and their form making gains ground. Currently regulatory documentation and requirements to projecting related to this typology of objects are absent.

The study of international and national experience allowed getting insight on the technology and possible functionality of information hubs. It was found out that every out of seven analysed innovative centres has its specificity and priority area. Several types of information hubs with the following priority directions can be distinguished:

- scientific and research with the big laboratory base (e.g., Stata-Centre in Boston, the USA);

- scientific and technical ones combining office and production functions as well (e.g., Skolkovo in Moscow, Russia);

- innovative and cultural ones combining educational and social functions (e.g., in Kaluga, Russia);

- cultural and informational ones with the prevalence of conference halls and open university spaces, information centres for tourists (e.g., in Tokyo, Japan);

- scientific and informational and technological ones directed at the conduct of 
interdisciplinary research and engineering practice with offices and studios for holding educational and research activity (e.g., in Caltech, the USA);

- data processing centres (data-centres) with automatic switch rooms, autonomous substations, generating station and boiler-room as well as the status of restricted access facility and scientific park providing wide access (e.g., in Samara, Russia or Mjansal, Finland);

- scientific centres of the new generation with experimental and production laboratories for approbation of pilot projects, business incubator, co-workings, conference centre and different public spaces (e.g., in Caen, Normandy).

Analysis of the general tendencies of the development of "smart cities" allowed to outline a row of problems to which the need in the following recourses can be assigned: 1) economic resource for the realization of the concept of intellectualization of a city presupposing compulsory budget co-financing; 2) personnel resource involving the presence of specialists having technological skills of producing innovations; 3) territorial resource that allows providing scalability, flexibility, safety, and approbation of smart city technologies.

Analysis of the being implemented innovative national and international technologies allowed using a typological approach to form the principal typology concept of a smart city's infrastructure objects $[4,5]$. Such an infrastructure is hierarchic and is formed by the following elements:

1) information hub with data centre controlling all the systems and objects of a "smart city", informational, scientific and production complexes;

2) intellectual objects as serving and connected with the information hub of the building and construction (data processing centres, developments of innovative technologies, scientific centres, Multimedia libraries and Media centres, information boxes, smart houses, intellectual parking lots, etc.);

3) intellectual systems representing linear objects (intellectual engineering systems: lighting, transport network, systems of video monitoring, WI-FI, power-efficient systems of heat supply, power supply and water supply, water disposal and use of "grey water", intellectual applications and IT services; intelligent systems for safety - information security, video monitoring, access administrative control, signalling and warning, fire safety and others);

4) information forms and details providing high level of the urban environment intellectualization (information stands and enquiry counters, smart stops and refuse collectors, interactive exhibits, media facades and media screens).

Every from the abovementioned typological elements of infrastructure of a smart city can be integrated in the existing urban environment on various finished ground levels streets, squares, quarters. On the level of a street it is more sensible to use such intellectual objects as parking lots, intelligent systems (transport navigation, video monitoring, WI-FI, commercial advertising), street furniture (enquiry counters, smart stops, smart refuse collectors) and others, linear objects are prevailing. On the level of a quarter representing urban texture objects from the largest ones (data centres, scientific centres, media centres, cultural centres, centres for IT development) to small pavilions, for example, information boxes are predominantly placed. Squares as well as streets being bobbin elements of the urban environment can become the starting position of the urban innovative technologies representation where information forms and details (interactive exhibits and road pavements, enquiry counters, festive video mapping and media facades) can predominantly find application.

The highest effectiveness of information technologies application is observed not in new cities, but in historic ones. One of the scenarios of a "smart city" concept development, according to Esaulov, is the "hybrid" one combining traditions and innovations. 
Historical and geographical approach to the peculiarities of Samara historical settlement formation revealed the following specific traits of the process of innovative technologies implementation into the existing urban environment formed gradually taking into account the concepts of formation of forest-park green belts [6].

The following issues can be referred to the local problems characterizing the situation in Samara: the absence of activity coordination of different parties interested in the information technologies implementation; immaturity of technological solutions in comparison to the world analogues; weak support from the population, and inertia towards innovations; low quality of housing and utility complex services.

With approbation in Samara Region of the large federal innovative project "Smart City. Successful Region" in 2018 is connected the search of new territorial and planning concepts of innovative technologies development in the regional centre, i.e. Samara. The same year the works on giving the city the status of historical settlement began, which activated the search for new planning solutions for realization of both strategic for the city projects.

Parabolic structure of the historical centre of the city developing from the "spit" of the river Volga and the river Samara in the last several years gives pause for reflexion about the city-planning significance of this place. Its part as the key compositional focus forming the historical landscape keynote of the city of Samara determining the structure of historical ensemble of planning network of streets and squares of historical settlement is doubtless. This is an important argument of the city-planning composition [7].

It was planned to build the stadium on this place to FIFA-2018, but later the project of territory planning with the positioning of the buildings of school, congress-hall and city hall was developed. However, such usage of the key for the city territory is not effective because of the big cost of release of this territorial resource, where currently the functioning river port with the adjacent territory of municipal warehouse and utility assignment is situated. One of the tendencies of large historical cities development is the displacement of production and municipal warehouse functions from the territory of the historical centre to the suburbs of the city. In this context the issue about the moving the river-port to another place becomes more acute every year.

The territory of the "spit" is close to the city centre, but does not have its own historic development, at the same time its utility use could be continued on the qualitatively new level. The absence of other large-scale territorial recourses for placement of the information hub in the historic centre serves as the basis for planning the main object of innovative infrastructure exactly within the boundaries of the given territory. Due to the parabolic form and regular planning structure of the centre of Samara the smart city infrastructure with its objects and linear systems will have resource potential for the development. The "spit" can become the place where the flows of information will go and be kept, where new technologies will be developed, the whole complex of various functional processes which was elicited while studying national and international experience will be executed.

To reach the set goals immediately in the historic core of Samara several stages of technological renovation were distinguished:

$1^{\text {st }}$ stage is technological renovation of Krasnoarmeiskaya St. as the main transportpedestrian axis of the historical centre and adjacent quarters' carcass;

$2^{\text {nd }}$ stage is the renovation of the city-forming social residential ambiance among five quarters around Kuybyshev Square;

$3^{\text {rd }}$ stage is the formation of the territory of advanced development of the former industrial area and industrial harbour of the "spit";

$4^{\text {th }}$ stage is technological renovation of engineering and social infrastructure of the city's historical core in general, landscape development and design of social spaces.

The strategic development directions of Samara urban space intellectualization are the following: transport, ecology, innovations, social and business centres, communication 
spaces and technologies, urban community, culture, education, innovative design of environment. Every direction requires conceptual creative study, which can be implemented, for example, within the boundaries of realization of the long discussed in the Samara community idea of the "Institute of the city".

Transfer to the new technological setup will require the development of concrete projects and suggestions, active discussion in the city community, coverage in mass media, reaching of public consent [8].

\section{Results}

As a result of the conducted research the suggestion on infrastructure of the smart city was developed, the finished ground levels of innovative technologies implementation in the structure of historic territories were determined [9]. The following typology of information hubs as the leading objects of the smart city infrastructure development was made: scientific and research ones, scientific and technical ones, innovative and cultural ones, cultural and informational ones, scientific and informational ones, technological ones, centres for data processing, scientific centres with experimental and production laboratories.

For the purposes of specification of practical use in the structure of "Spit" model project suggestion on the formation of scientific-project centre with experimental and production laboratories under the brand of "Park-plant" on one of the plots of land of the former plant territory of the valve plant was developed. Herewith, one of the social aims is the dealing with the conflict of the past and the future in the way of life of the citizens, acceptance of the new technological setup. Innovative urban environment of "Park-plant" becomes original and accessible ground for a wide range of citizens, laboratory of environmental design of the future public spaces of the city and excursion to the "city of the future" for pupils and students. "Park-plant" is being positioned as the scientific and research and educational centre, accessible for researchers, students and citizens. Technopark Zurich, Switzerland can serve as an attractive example and analogue of such a publicly accessible technopark. The technopark was formed in 1993 on the territory of the former industrial area; currently it is the scientific and educational centre of the cutting-edge technologies open for the city (fig. 1).
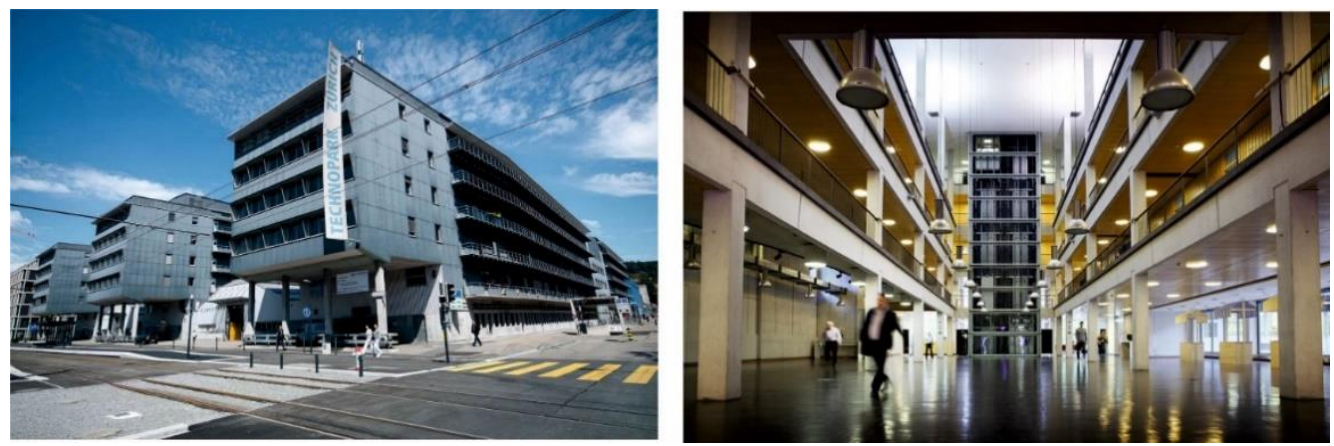

Fig. 1. Technopark Zurich, Switzerland.

On the territory of Samara "Park-plant", it is suggested to places scientific and industrial laboratories of the following intelligent (but real as well) city technologies:

- system of city traffic modelling and control;

- hardware-software complex "Smart parking lot"; 
- intelligent systems of video control;

- monitoring system of contiguous areas;

- crisis situations warning system;

- "Individual guide";

- applications with the use of technology of virtual and augmented reality;

- AR - application "Modelling of public space";

- technologies and production of information boxes;

- technologies of modelling social and economic (including fiscal) subsystems of the urban environment;

- technologies of intellectual lightning;

- production of containers for household rubbish separate collection;

- restoration energy saving solutions;

- centre for city BIM-technologies;

- collection of water from roofs for watering lawns;

- projecting with co-participation and some others [10].

The aim of the innovative ground "Park-plant" is, thus, creation and support of electronic ground for functioning and reflection of all programmes for improvement, building, and reconstruction of dwelling, roads and social objects in the historical centre of the city.

Mechanisms include redevelopment of industrial zone and adjustment of industrial buildings for modern use, combination of organizational efforts of the triad of urban development agents. The end expected result is the creation of modern innovative technological cluster as a factor of enhancement of the region investment attractiveness. Data on the project: gross construction area is 2,6 hectares, the number of working places is 700 ones, the equipment cost of production lines is 285 million roubles.

The organization structure of model projects advancement is suggested according to the concept "Triad of urban development agents" (fig.2), in which flagship university (Samara State Technical University) - urban community (city administration and community) park-plant (centre for the cutting-edge technologies) interact within the project programme.

The effects of the development of the being renovated territory of the city historic core will the following ones:

- involvement in the investment activity of the big territory of the historic development in the nearest 10 years;

- increase of the volume of new real estate in the city historic development;

- increase of the tax potential of the territory;

- attraction of new population and the process of gentrification in the historic core of the city.

Thus, Samara has an opportunity to increase its status as a megapolis providing huge opportunities for comfortable living, business, creation and educational programmes. 


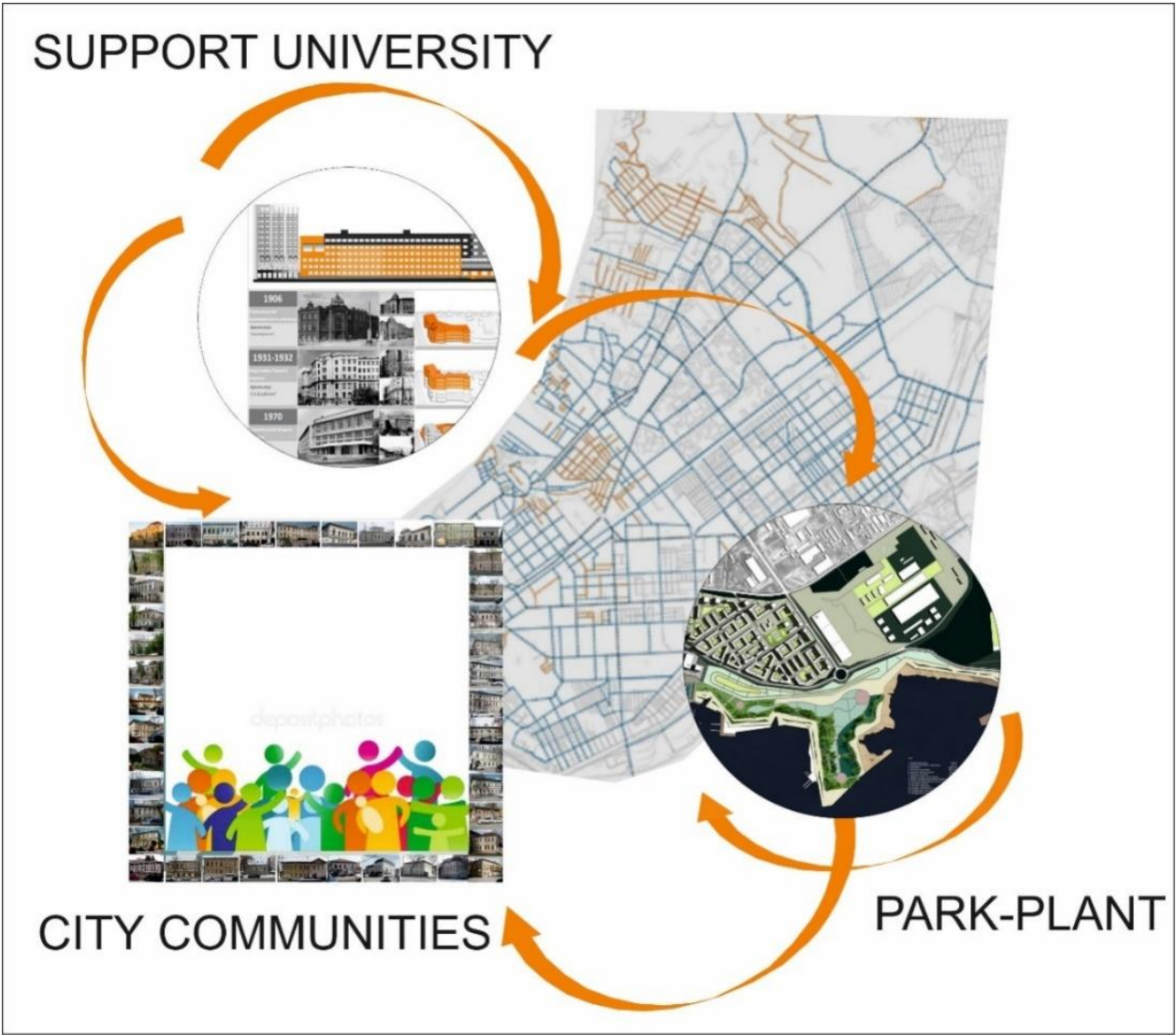

Fig. 2. Triad of urban development agents.

\section{Discussion}

Envisioning of intellectualization of historic city over the whole range of suggestions aroused broad discussion among the interested parties: scholars, university and academic community, industrial and business partners of the university. The discussion was held by the interdisciplinary team in the form of open discussion on the principles of coparticipating projecting of the type of Design Charrette. In the urban community technological initiatives were perceived as a stimulus for historic Samara revival, and taking into account the city historic centre heritage it was claimed to be the territory of advanced development.

The research is intended to be continued in the direction of the development of construction code, rules and guidelines to the projecting of smart cities infrastructure, in which the innovative centres being the objects of absolutely new typology are becoming the key element.

\section{Conclusions}

The article outlines general and local problems of information technologies implementation in the structure of existing cities. The analysis of the international and national experience allowed eliciting 8 types of innovative centres, each of which has its intellectualization 
brand depending on profile functions. As illustrated by Samara, the concept of information infrastructure serving the intellectualization of historic city and organizational structure of "smart city" model projects advancement by "Triad of urban development agents" (flagship university - urban community - park-plant) is offered. Final levels, on which innovative technologies can be used, are determined; model projects are offered in the structure of historic territories. The significance of the research results is in the opportunity of practical implementation of the developed concept of intellectualization of existing cities within strategic, territorial planning.

\section{References}

1. C.F. Caragliu, Del Bo, Technological Forecasting and Social Change 142, 373-383 (2019) doi.org/10.1016/j.techfore.2018.07.022

2. M. Nilssen, Technological Forecasting and Social Change 142, 98-104 (2019) doi.org/10.1016/j.techfore.2018.07.060

3. F.P. Appio, M. Lima, S. Paroutis, Technological Forecasting and Social Change 142, 1-14 (2019) doi.org/10.1016/j.techfore.2018.12.018

4. A.H. Alavi, P. Jiao, W.G. Buttlar, N. Lajnef, Measurement 129, 589-606 (2018) doi.org/10.1016/j.measurement.2018.07.067

5. E. Ismagilova, L. Hughes, Y.K. Dwivedi, K.R. Raman, International Journal of Information Management 47, 88 - 100 (2019) doi.org/10.1016/j.ijinfomgt.2019.01.004

6. A. Kukina, Urban Morphology 10, 145-146 (2006)

7. J.W.R. Whitehand, Urban Morphology 14, 3-4 (2010)

8. I. Capdevila, City 13, 8-12 (2018) doi.org/10.1016/j.ccs.2017.05.003

9. Á. Palomo-Navarro, J. Navío-Marco 42, 872-880 doi.org/10.1016/j.telpol.2017.10.002

10. S. Andreani, M. Kalchschmidt, R. Pinto, A. Sayegh, Technological Forecasting and Social Change 142, 15-25 (2019) doi.org/10.1016/j.techfore.2018.09.028 